\title{
عبقرية اللغة العربية ودورها في التقارب المعرفي والتلاقح الثقافي بين الشعوب
}

\author{
Abdullah Alsuwaiket* \\ Majmaah University, Saudi Arabia
}

The Genius of Arabic Language and its Role in the Cognitive Convergence and Cross-Cultural Fertilization between Peoples

\section{E-Mail Address}

a.alswiket@mu.edu.sa

${ }^{*}$ Corresponding Author

\section{Keywords}

Arabic language;

geniality;

cognitive convergence;

cultural cross-fertilization

\begin{abstract}
The Arabic language is the spirit of the Arab nation, the title of its identity, and the inclusion of its culture, and when it is preserved by its people, they will be able to be the builders of others' minds and the proponents of its flags among the languages of nations and peoples. Accordingly, the significance of the study mentioned the geniality of the Arabic language, its properties, its spread in the world. The problem of the study is the universality of the Arabic language after Islam, its major properties, the extent of its spread, its impact. The study will follow the analytical descriptive methodology in tracing this problem and studying its terms. The study revealed the universal position of the Arabic language among other languages of the world that made it a title of human civilization, cultural reference, and the tool of communication between the Arab peoples and non-Arab.
\end{abstract}

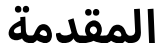

اللغة العربية رمز هوية الأمة العربية، وحاملة لغة القرآن الكريم، وناقلة الثقافة العربية عـبر القرون، وعن طريق تلك اللغة اتصلت الأجيال بالأجيال، والأمم بالأمم ، والشعوب بالشعوب، عبر القربه القرون وتعاقب القبه

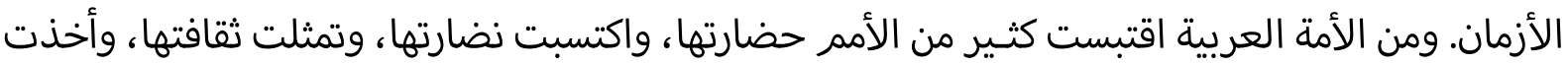

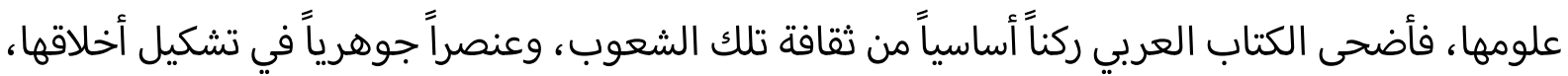
وبناء أفكارها، وفي الحين الذي أضحت اللغة العربية نقطة التقاء العرب بالشعوب الأخرى، وفي الوقت وتئ الذي غدت فيه اللغة العربية أداة التلاقح الثقافي والتبادل المعرفي، سجلت اللغة العربية نقطة اهتمام البشرية على اختلاف ألسنتها وألوانها، فهي لغة نشأت فتية على غير مثال، يقول الفرنسي إرنست رينان:

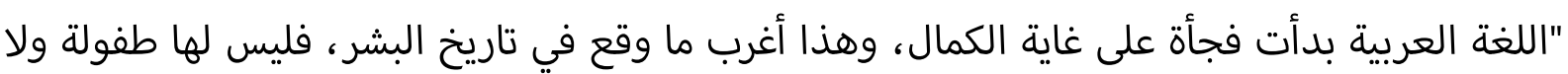
شيخوخة ظهرت لأول مرة تامة مستحكمة، ولم يمض على فتح الأندلس أكثر من خمسين سنة حتى اضطر 
رجال الكنيسة أن يترجموا صلواتهم بالعربية ليفهمها النصارى"، وهو كلام صحيح؛ إذ إن اللغة العربية قد وصلت إلى درجة الكمال عند أمة كانت أمية غالبيتها من الرحَّل. تهدف هذه الدراسة إلى الإجابة عن عدد من الأسئلة المهمة التي تتعلق بعالمية اللغة العربية بعد العدا ظهور الإسلام ، وأبرز مزاياها، ومدى انتشارها، وتأثيرها، وتتركز الأسئلة فيما يلي: (ا) كيف أصبحت الإسئل اللغة العربية لغة عالمية بعد ظهور الإسلام؟؛ (؟) ما سمات اللغة العربية الصوتية والصرفية و التركيبية، ومزاياها التي جعلتها تتفرد بين لغات العالم؟؛ (ّ) كيف انتشرت اللغة العربية في أرجاء العالم في القديم والحديث؟ ومزائ

توجد دراسات كثيرة عن اللغة العربية وخصائصها بشكل عام، ولكن الذي يلفت النظر في دراستان تشابهان هذه الدراسة من حيث العنوان، لكنهما في المحتوى مختلفتين، وهما: (ا) كتاب مطبوع تحت عنوان: "عبقرية اللغة العربية"، للدكتور عمر فروخ، وهو كتاب مطول بلغ ثلاث مئة صفحة، لكن مفردات هذا الكتاب تتناول المدارك القديمة في اللغة، ومراحل القياس في تاريخ اللغة العربية، وبعض فهونه القضايا في الشعر العربي كالنجوم، والغزل، والنسيب، ولم يتطرق الكتاب إلى عالمية اللغة العربية، ولا خصائصها، ولا أثرها في اللغات، ولا عوامل انتشارها في العالم ، وهي نقاط تناولتها دراستي بشيء من التفصيل؛ (ז) كتاب مطبوع تحت عنوان: "عبقرية اللغة العربية"، لمحمد عبدالشافي القوصي، وهو كتاب بلغ مئتين وستة وعشرين صفحة، تحدث فيه عن تاريخ العربية وتطورها، وأبرز لهجاتها، وخصائصها، وعجائبها، ووظائفها، ولم يتطرق الكتاب إلى عالمية اللغة العربية، ولا عوامل انتشارها في شتى بقاع العالم ، وهما موضوعان مهمان عند دراسة اللغة العربية. ترمي هذه الدراسة إلى تحقيق عدد من الأهداف، منها: (ا) بيان مكانة اللغة العربية بين لغات العالم ، مهان وعبقريتها الفذة التي جعلتها تتبوأ مكانة مرموقة بين لغات الشعوب؛ (؟) إثبات المركز العالمي الذي تحتله،

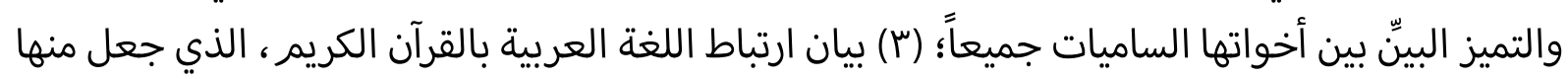
لغة مقدسة؛ (ع) تحديد مكانة اللغة العربية بين اللغات المعاصرة، وذلك من خلال مقارنتها، وإظهار قدرتها على الوفاء بمتطلبات العصر الحديث؛ (0) تسعى الدراسة إلى إبراز مزايا هذه اللغة التي أكسبتها التفرد، بما تمتلكه من مرونة، واتساع، وطواعية مفردات على المستوى الاشتقاقي، والصوتي، والتركيبي؛

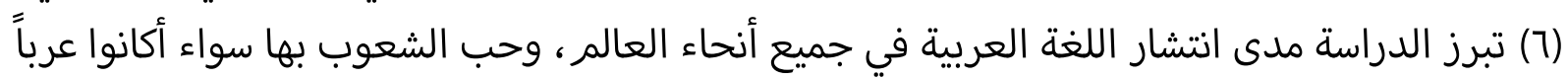
أم عجماً؛ (V) تسعى الدراسة إلى بيان الأثر الكبير الذي تركته هذه اللغة في الكثير من لغات الغات العالم.

\section{منهج البحث}

اتخذت الدراسة المنهج الوصفي التحليلي منهجاً لها دراسة هذه المشكلة وتتبع ظواهرها وتحليل مفرداتها. وتكونت هذه الدراسة من أربعة مباحث، وتحت كل مبحث عدة مطالب، وهي على النحو الآتي: المبحث الأول: عالمية اللغة العربية؛ (I) عالمية اللغة العربية بعد ظهور الإسلام؛ (؟) عالمية اللغة العربية في عصرنا الحاضر. المبحث الثاني: مزايا اللغة العربية وتفردها بين لغات العالم؛ (ا) سعة اللغة العربية؛ 
(Y) مرونة اللغة العربية، وطواعية مفرداتها على ثلاثة مستويات: المستوى الاشتقاقي، على مستوى

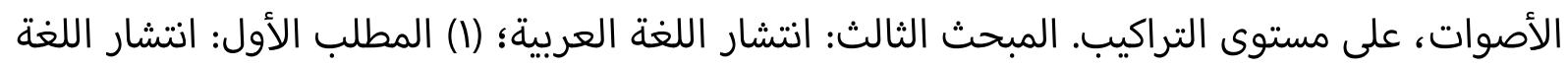

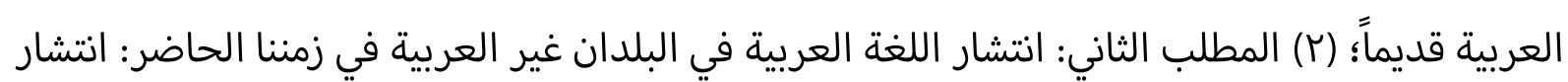
اللغة العربية في الولايات المتحدة الأمريكية، انتشار اللغة العربية في إسبانيا، انتشار اللغة العربية في ألمانيا، انتشار اللغة العربية في إندونيسيا، انتشار اللغة العربية في الهند، انتشار اللغة العربية في الصين. المبحث الرابع: تأثير اللغة العربية في اللغات الأخرى.

\section{نتائج البحث والمناقشة}

أ. عالمية اللغة العربية

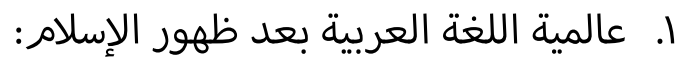
السابر لنشأة اللغة العربية يجد أنها ولدت وترعرعت في أحضان شبه الجزيرة العربية المستقرة تاريخياً وجغرافيا؛ مما وفر لها أسباب الحفظ والتمكين لعدة قرون قبل الإسلام. وبعد أن انبلج نور الإسلام وأقرَّ أن اللغة العربية هي اللغة الحاملة لكتاب الله تعالى، باتت لهذه اللغة الميـزة العظمى على أخواتها الساميات جميعاً، بل إنها تفوقت على أكثر لغات العالم الحية بما تتصف به من مميـزات، وبما تتمتع به من سمات، جعلت منها لغة عالمية لا يمكن أن يدخل إنسان في دين الإسلام إلا بعد أن يتعلمها أو يتعلم

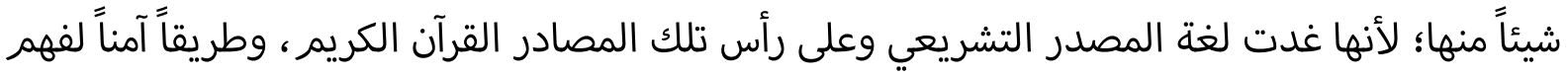

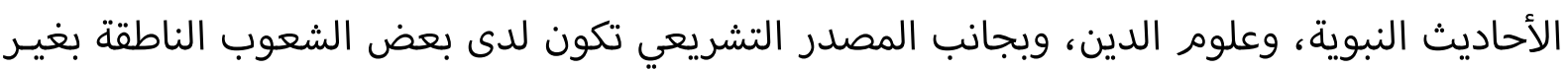
العربية حب وعشق لهذه اللغة التي حببها القرآن الكريم إلى قلوبهم، فعشقوا معها أدبها، وتراثها، وعلومها النظرية والتطبيقية منذ بزوغ الإسلام حتى يومنا الحاضر ، فهذا أبو الريحان البيروني -ذلك العالم الرياضي والفيلسوف الذي ولد في ضاحية خوارزم في أوزبكستان، أي أنه من أصل غيـر عربي- كانت تحيط الِّاط به العديد من القوميات والأعراق غير العربية، نراه يفخر باللغة العربية ويعجب بعبية بعريتهائها، فيقول: "والله لأن أُهجى بالعربية أحب إلىَّ من أن أمدح بالفارسية (al-Mubārak, 1979, p. 19). ويعتـرف المستشرق الألماني "يوهان فك" بعالمية اللغة العربية، فيقول: "إن العربية الفصحى لتدين حتى يومنا هذا بمركزها العالمي أساسياً لهذه الحقيقة الثابتة، وهي أنها قد قامت في جميع البلدان العربية

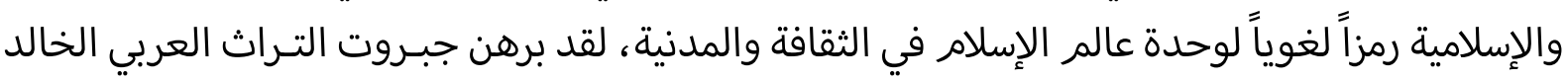
على أنه أقوى من كل محاولة يقصد بها زحزحة العربية الفصحى عن مقامها المسيطر ، وإذا صدقت البوادر جيترور al-Jundī, ( ولم تخطئ الدلائل فستحتفظ العربية بهذا المقام العتيد من حيث هي لغة المدنية الإسلامية مئية

وحينما أصبحت اللغة العربية لغة عالمية مقدسة بعد ظهور الإسلام؛ فقد كان لزاماً أن تكون لغة الدين الحق الذين تؤمن به أمة المليار التي تمثل ربع سكان الكرة الأرضية، فهي في نظر العربي والأعجمي 
أفضل اللغات، وأحقها بالحياة والديمومة والبقاء، وبذلك استطاعت أن تجمع تحت رايتها أمماً وأعراقاً

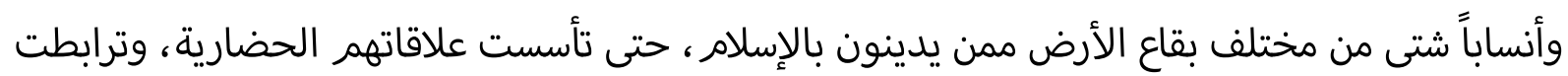
أواصرهم الاجتماعية، واتصلت ثقافاتهم ، وتوحدت أساليب تفكيرهم وطرائق تعبيـرهم ، وأمكن التفاهم

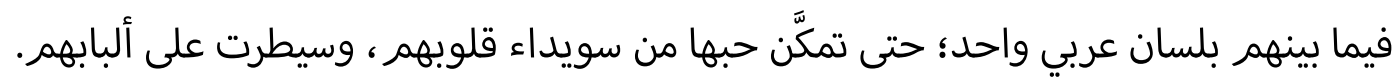

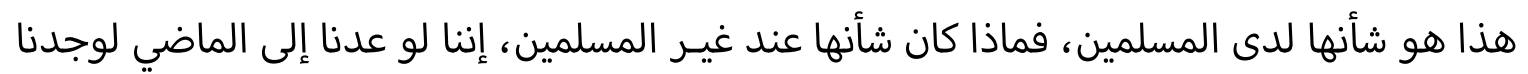
أنه "في ظل الخلافة الأموية والعباسية -ومع مرور السنوات- باتت اللغة العربية لغة الشعائر المنتشرة في هذه الفترة كالشعائر المسيحية في منطقة الوطن العربي وفي كل من: كنائس السريان، والروم،

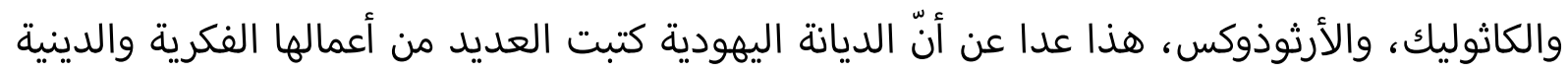
باللغة العربية في العصور الوسطى (Abd al-Qādir, 2017‘)، ثم أصبحت بعد ذلك عنوان الحضارة

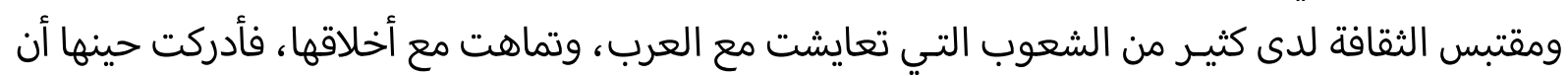
هذه اللغة ستكون لغة التخاطب بين قبائل العرب وغيـر العرب؛ ذلك أنه لا إسلام إلا بتعلم كتاب الله تعالى أو جزء منه. فالعربية هي لغة القرآن، وهو الكتاب المهيمن على ما سواه من الكتب السماوية، وهذا يقتضي أن تكون اللغة العربية هي صاحبة الهيمنة على غيرها من اللغات، وقد اختارها الله أن تكون لغة كتابه العزيز؛

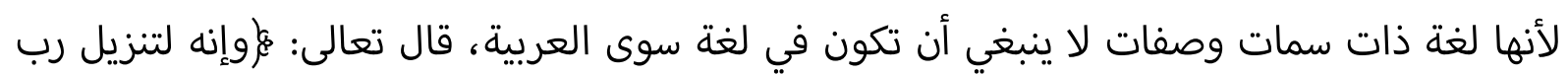
العالمين، نزل به الروح الأمين، على قبلك لتكون من المنذرين، بلسان عربي مبينجة (-

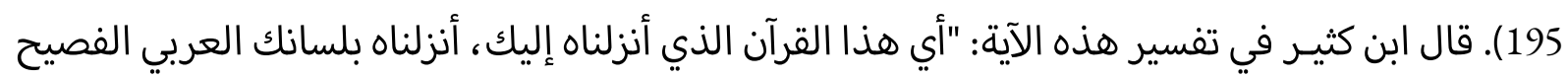

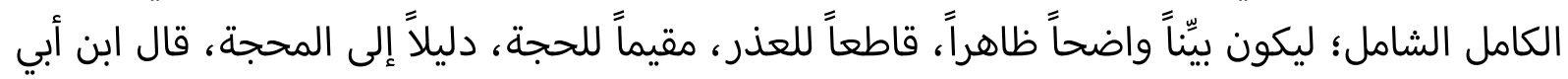

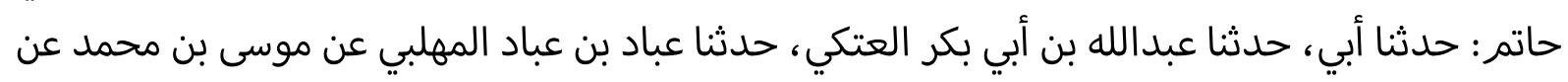

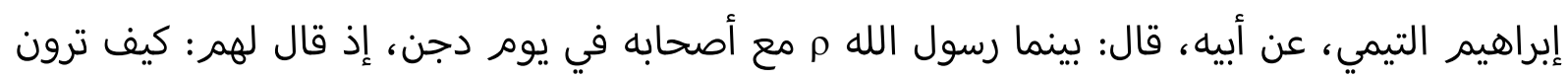
بواسقها؟ قالوا: ما أحسنها وأشد تراكمها، قال: فكيف ترون قواعدها؟ قالوا: ما ما أحسنها وأشد تمكنها! قال: فكيف ترون جَونها؟ قالوا: ما أحسنه وأشد سواده! قال: فكيف ترون رحاها استدارت؟ قالوا: ما أحسنها وأشد استدارتها! قال: فكيف ترون برقها؟ أوميض أم خَفو أم يشق شقاًً قالوا: بل يشق شقاً، قال: الحياء

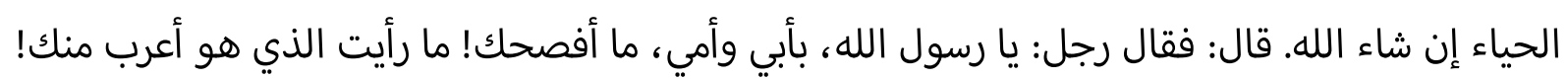
قال: فقال: حق لي، وإنما أنزل القرآن بلساني والله، واللسان يوم القيامة بالسريانية، فمن دخل الجنة تكلم بالعربية. رواه ابن أبي حاتم (359-358 (Ibn Kathīr, n-d., pp. ومن ذلك الحديث يُعلم أن سر فصاحة النبي؛ لأن الله تعالى أناط بلسانه كلامه المنـزل، وبفضل هذا التنـيل غدت اللغة العربية لغة عالمية لن تزول حتى يرفع الله هذا الكتاب عن الأرض، فهي محفوظة

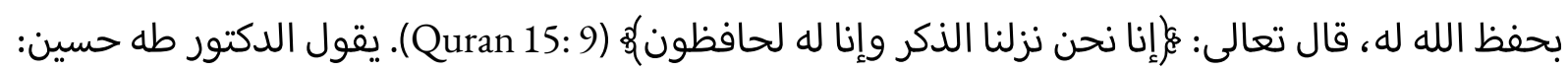

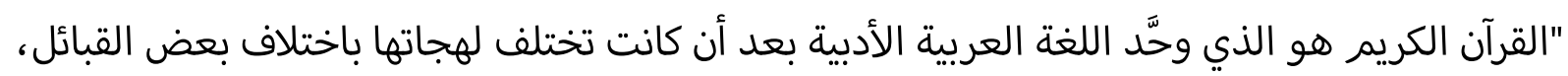
وفضل القرآن إثر نزوله، هو أنه جعل لغته لغة أدبية للعرب جميعاً، ثم لغير العرب من الأمم التي 
خضعت لسلطان الأمة العربية بعد الفتح، فالقرآن إذنْ لم يكتفِ بقصر اللهجات القبلية على أن تظل لغة ألغة

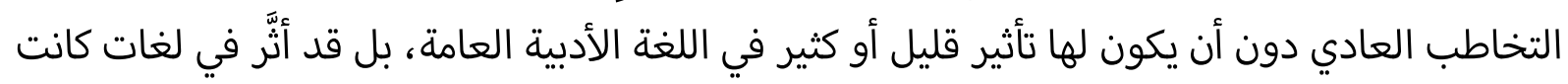

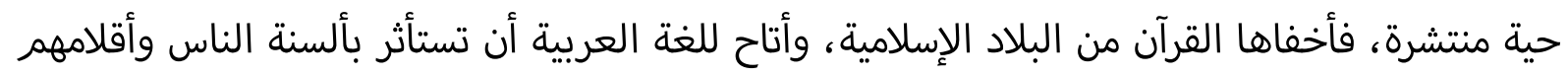

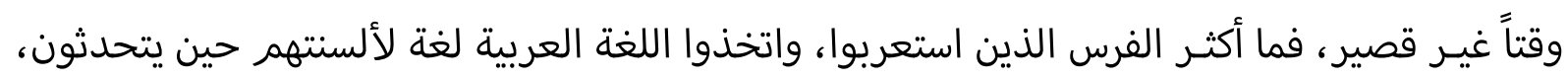

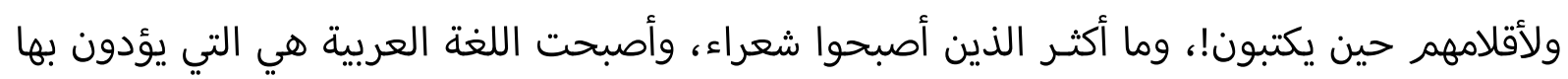

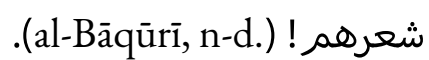
يقول المستشرق عبد الكريم جرمانوس :" إنّ في الإسلام سنداً هامّاً للغة العربية أبقى على روعتها

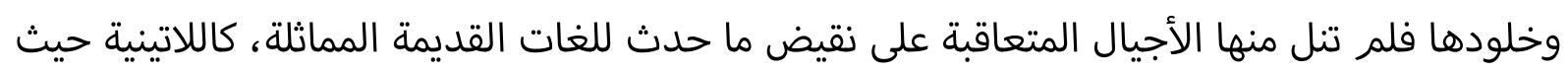

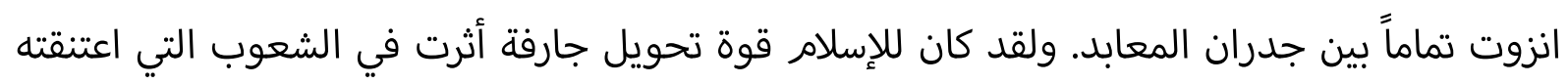

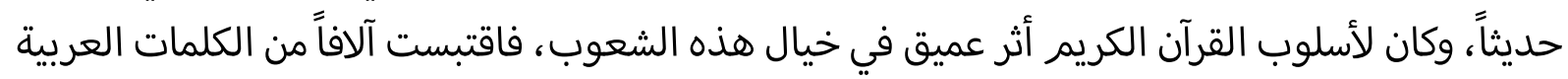
ازدانت بها لغاتها الأصلية فازدادت قوةً ونماءً (al-Jundī, 1982).

r. عالمية اللغة العربية في عصرنا الحاضر

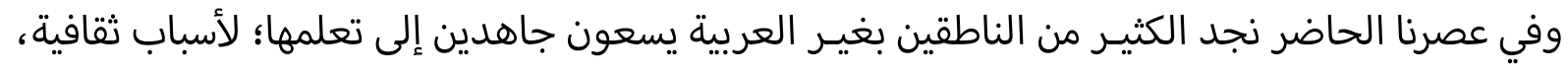

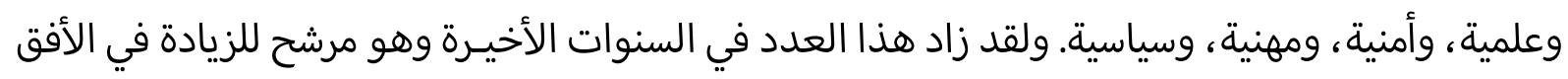

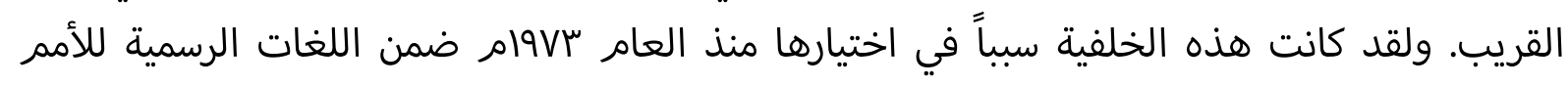

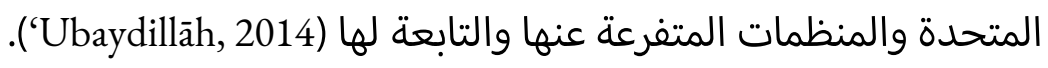

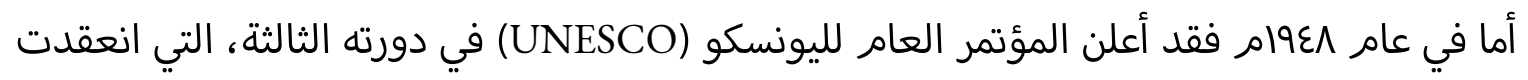

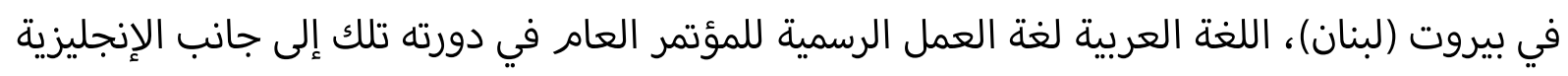

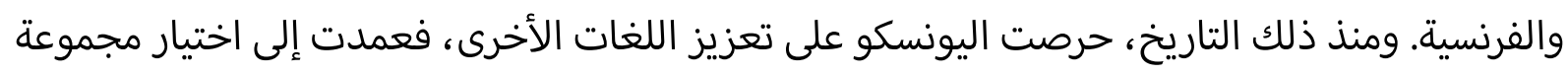

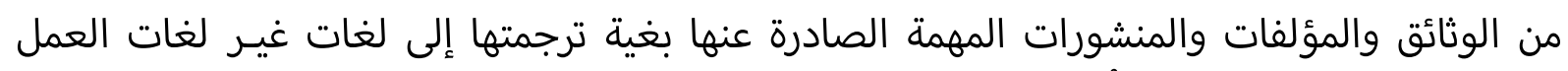

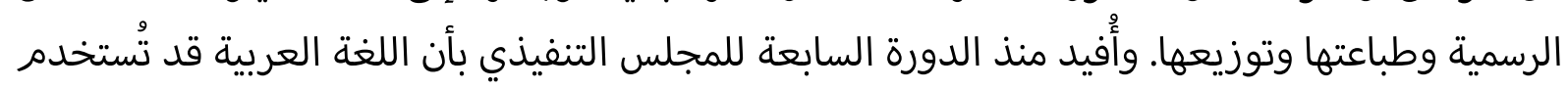

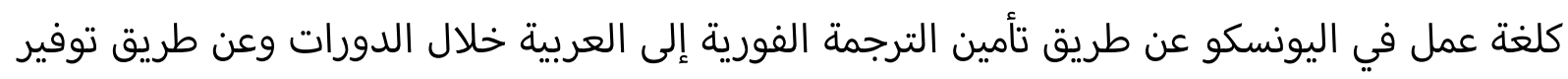

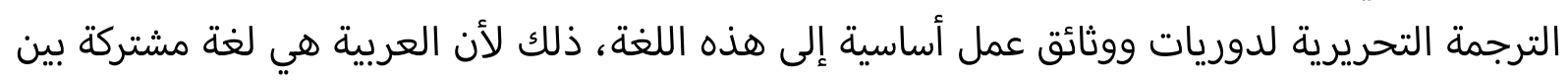
عدد كبير من الدول الأعضاء.

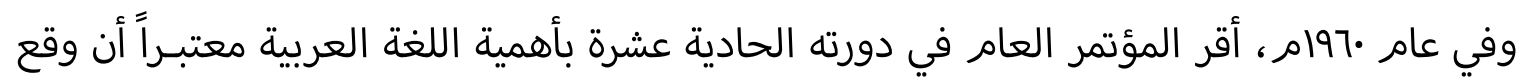

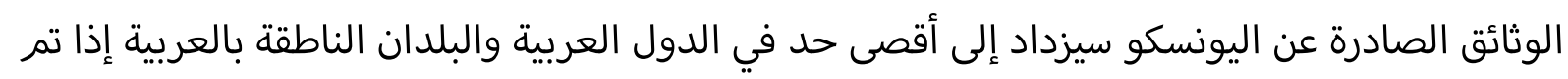

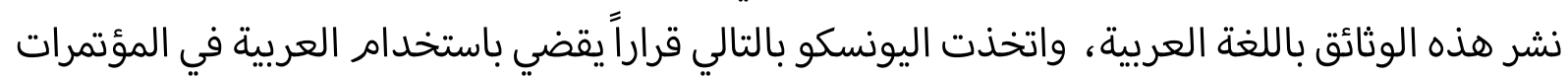

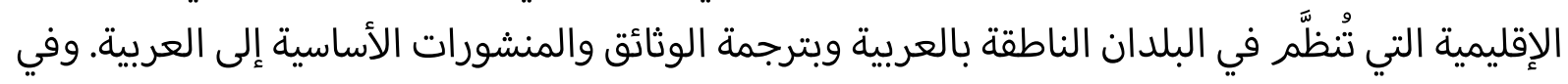
عام عVVام اعتمد المؤتمر اللغة العربية كلغة عمل وقرر وضعها في نفس المكانة التي تحظى بها اللغات 
الأخرى، أما مسألة استخدام اللغة العربية كلغة عمل في دورات المجلس التنفيذي، فأُدرجت في جدول

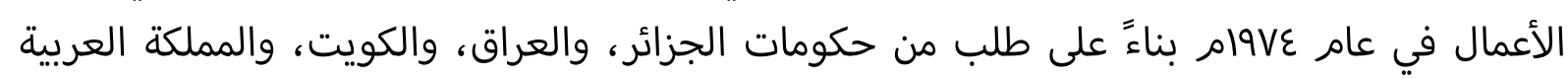

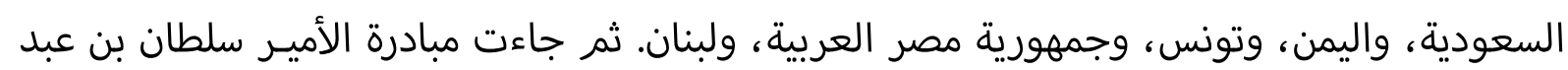

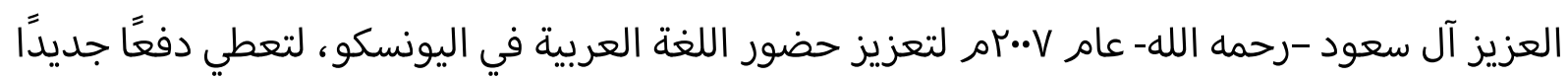

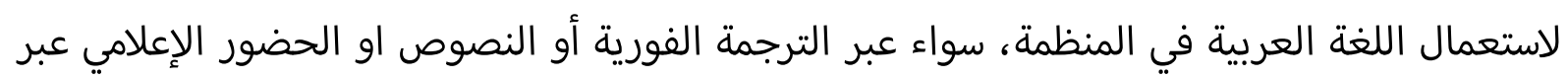
شبكة الإنت رنت (www.unesco.org)

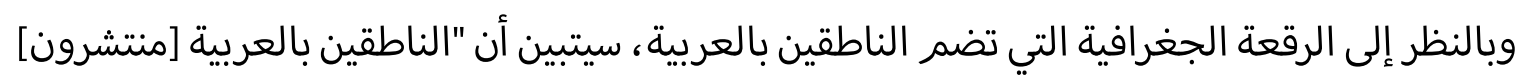

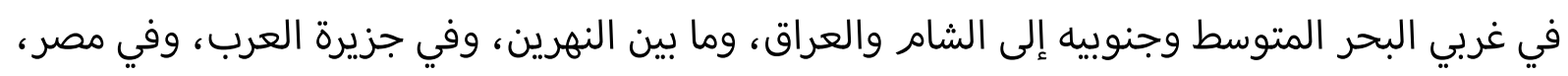

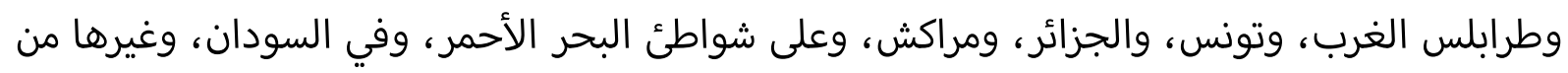

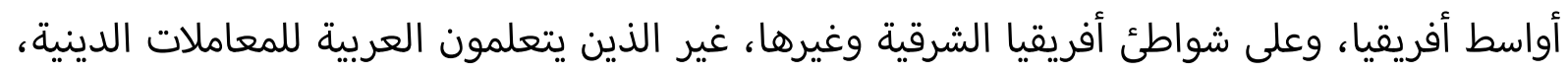

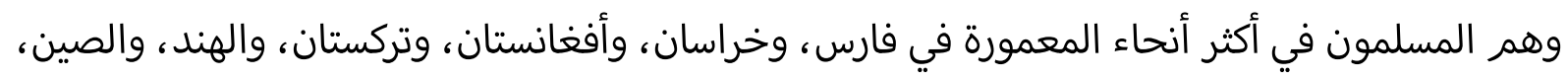
وجزائر الهند الشرقية، وسائر البلاد التي دخلها الإسلام في القارات الخمس (Zaydān, 2012, p. 52).

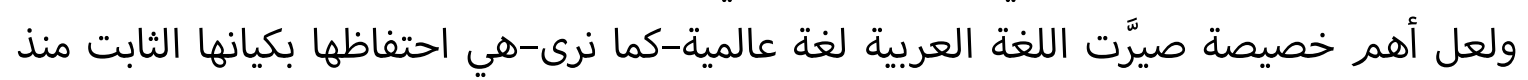

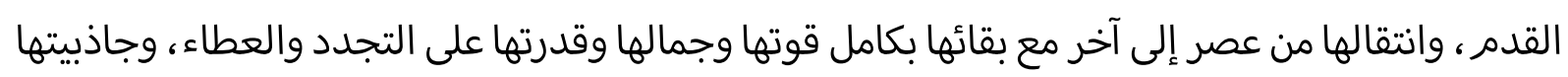

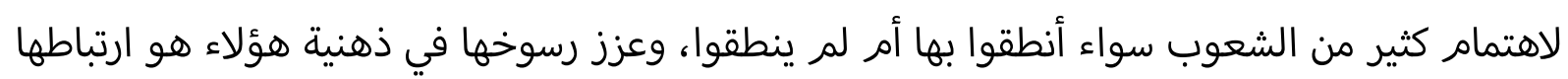

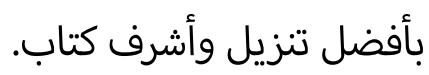

ب. مزايا اللغة العربية وتفردها بين لغات العالم

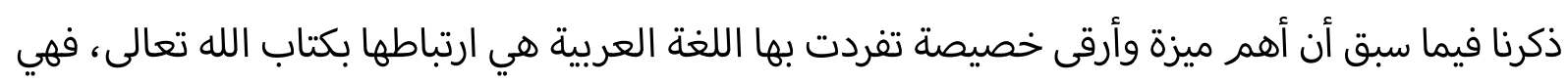

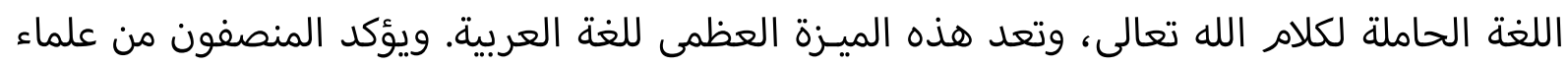

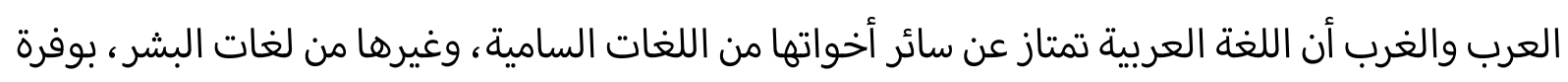

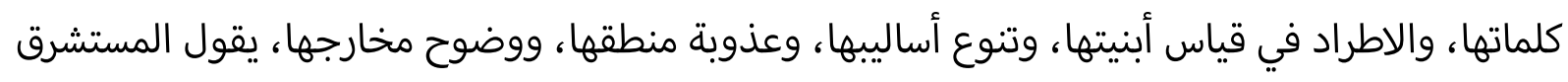

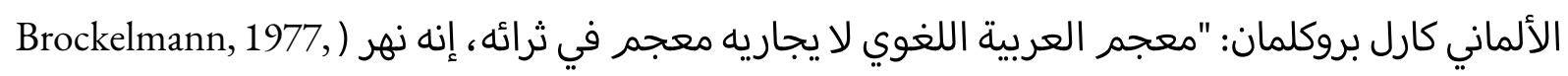

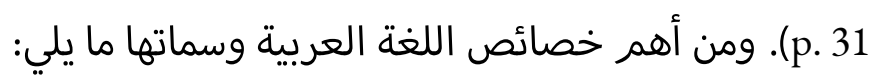

ا. ال سعة اللغة العربية سعة اللغة العربية، ولعل أقرب تعليق يوصِّف هذه السمة ما جاء عن الإمام الشافعي -رحمه الله- قوله:

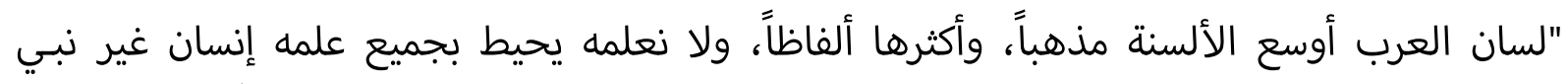

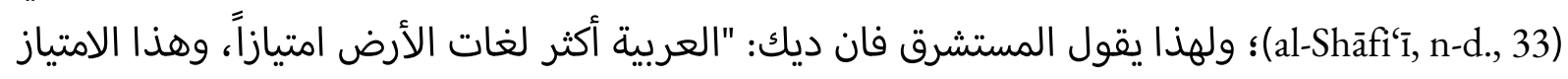

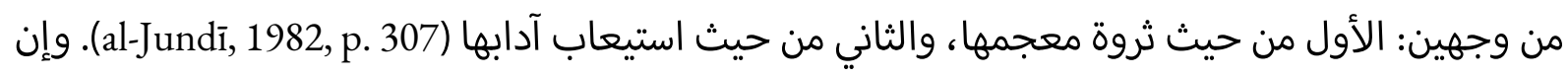

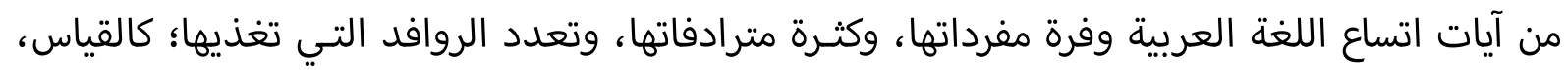


والتوليد، والاشتقاق، والنحت، والتعريب، ووجود الفروق اللغوية، ولعل أول من وضع للأخير كتاباً

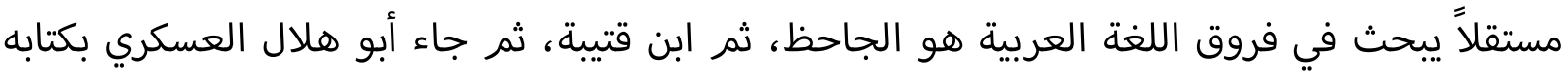

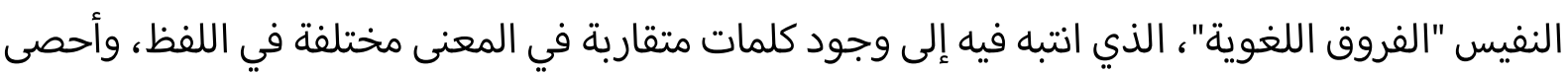

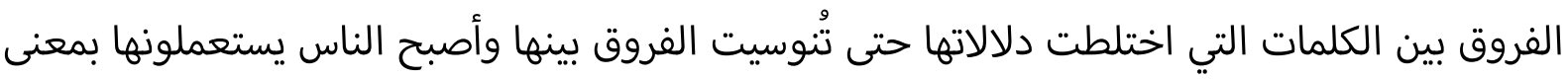

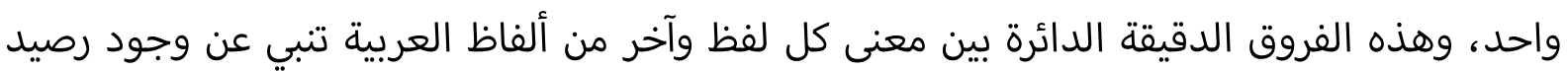
معجمي اتسمت به العربية دون ما سواها. وإن من اتساع اللغة العربية وجود معاجم وقواميس وموسوعات تدرس الكلمات العربية ومعانيها وجذورها وعناصرها، والعلاقات الدلالية بين الكلمات؛ مما يدل على وجود كم هائل من المفردات سواء

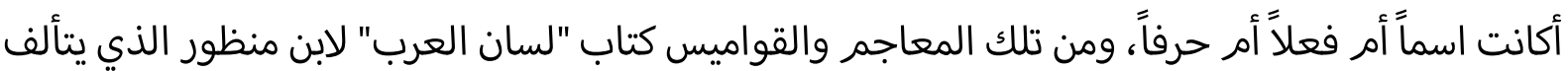
من خمسة عشر جزءاً، وكتاب الصحاح للجوهري، ومن تلك المعاجم والقاموس المحيط، للفيروز آبادي، وغيرها.

r. مرونة اللغة العربية وطواعية مفرداتها يقول أنور الجندي: "والعنصر الثاني الذي أبقى على اللغة العربية هو مرونتها التي لا تُبارى، فالألماني

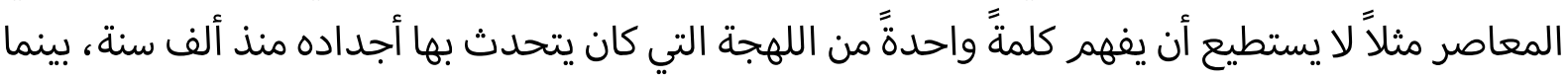

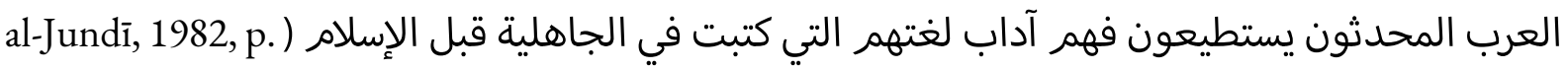

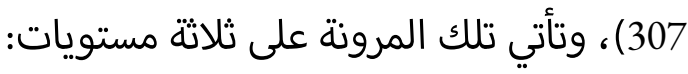

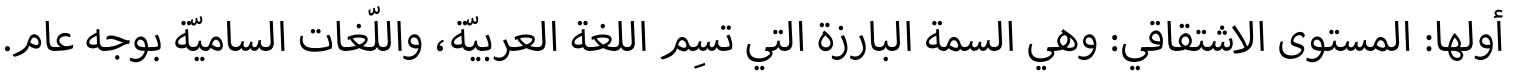

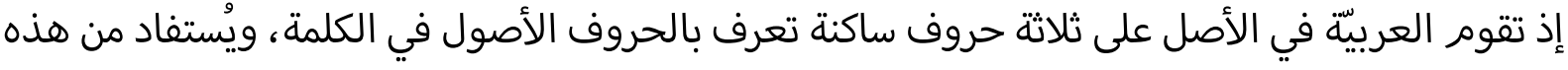

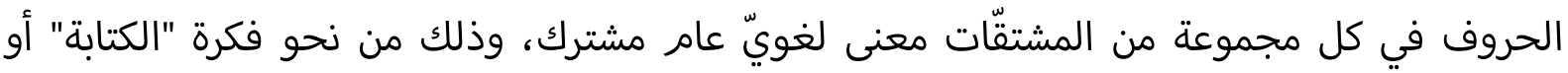

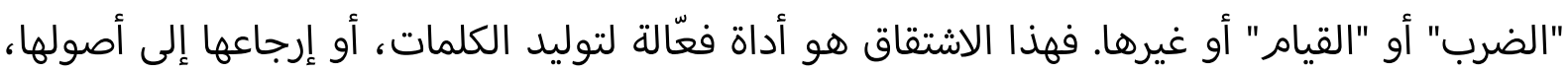

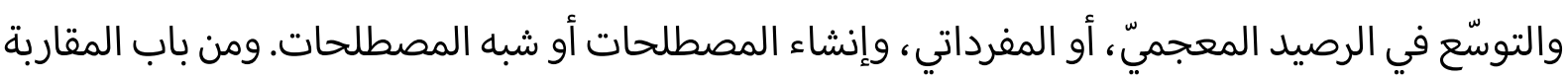

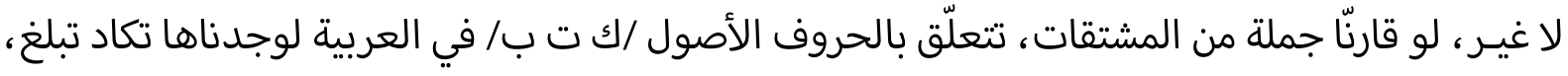

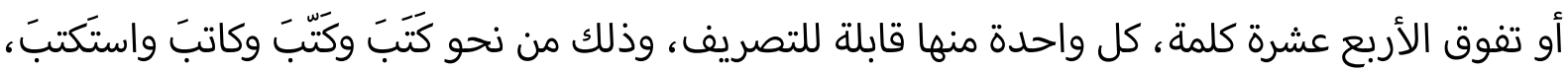

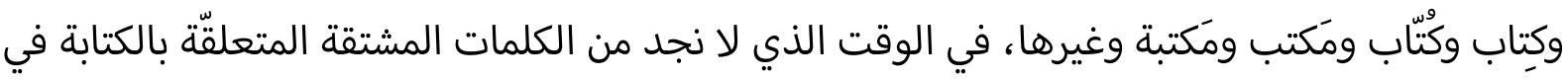

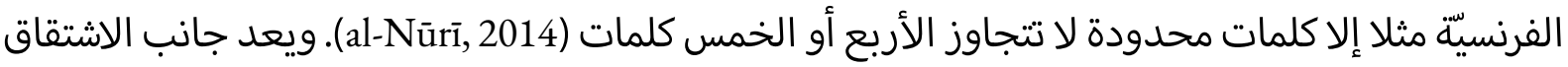

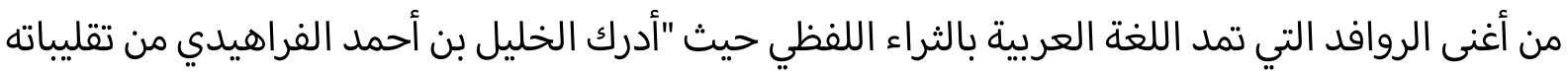

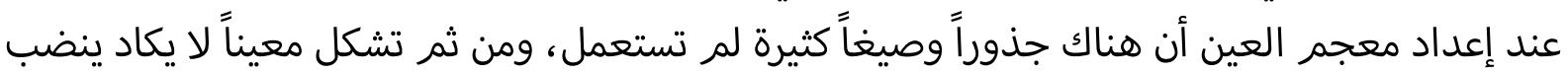
للألفاظ الجديدة والثراء المعجمي للغة العربية (al-Yūsuf, 2017, p. 14).

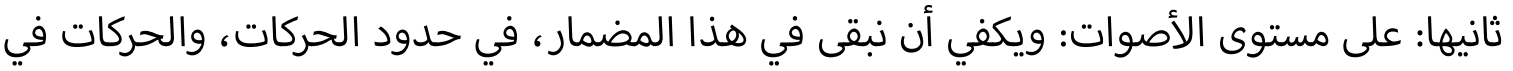

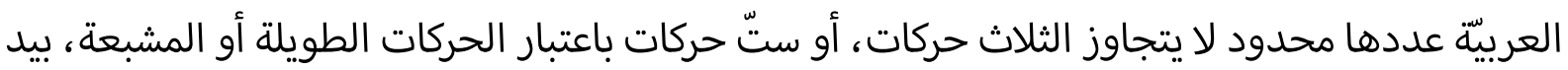


أنّ نظام الحركات في العربيّة يتمتّع بجملة من الوظائف التي لا تخفى عن العين المراقبة، وهي تتمثّل في الوظائف الآتية: أ) وظيفة صوتيّة: إذ من شأن الحركة أن تحرّك الحرف، والحرف في الأصل ساكن غير متحرّك على حدّ رأي الخليل.

ب) وظيفة صرفيّة: إذ من شأن الحركة أن تميّز بين الصيغ الصرفيّة، وذلك من نحو صيغة اسم الفاعل

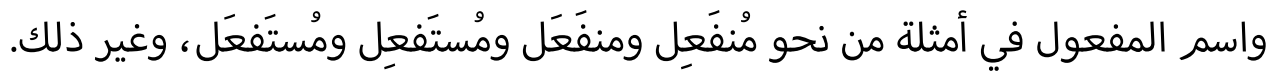

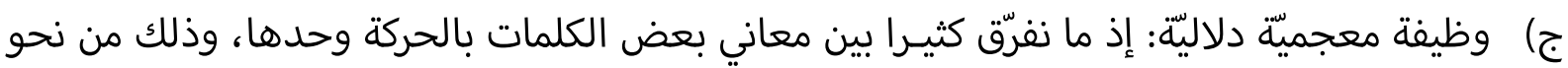

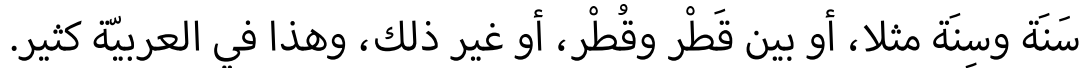

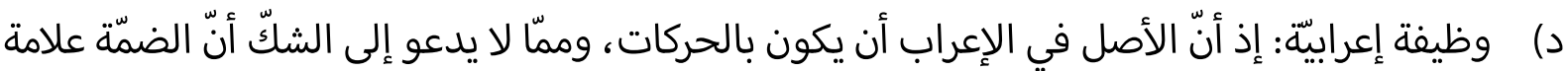

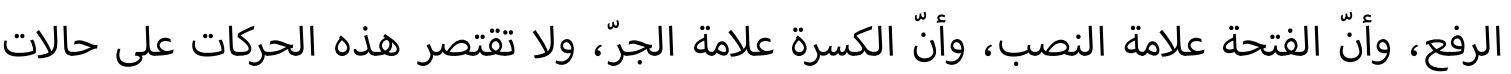
الإعراب وحدها، وإنمّا تتعلّق بعلامات البناء أيضا (al-Nūrīi, 2014).

وجدير بالذكر فيما يتعلق بالجانب الصوتي للغة العربية أنها تستخدم كامل النطاق النطقي للإنسان؛ إذ تستعمل أصواتها النطاق الذي يبدأ من أقصى الحلق (الحبال الصوتية) إلى الشفتين، كما تضيف إلى ذلك ظاهرة لا تكاد تعرف في اللغات الأخرى المشهورة، وهي ظاهرة الإطباق، الذي يؤدي إلى التمييـز بين السين والصاد والتاء والطاء مثلاً، من هنا يمكننا الزعم بوجود خصائص صوتية أو نطقية مميزة للغة لألة العربية قد لاتوجد في لغة أخرى (al-Yūsuf, 2017, p. 12). ثالثها على مستوى التركيب: ذلك أنّ العناصر المنتظمة داخل التركيب أو الجملة لها من المرونة ما لا نجده في أكثر اللّغات. وهذه المرونة مردّها إلى ظاهرة الإعراب والمحلات الإعرابية التي تتمتّع بها العربيّة ،

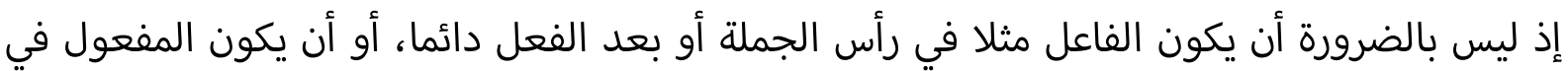
طرفها، وإنمّا يمكن لأيّ عنصر من عناصر الجملة أن يتوزّع بالكيفيّة التي تحلو للمتكلّم المستمع، فيقدّم إِّر

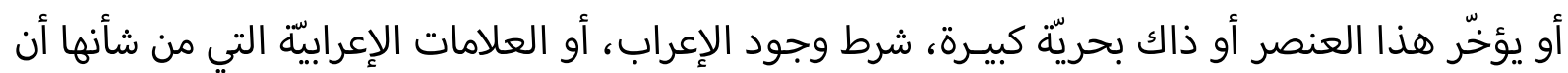
تميّز العناصر التي تأتلف منها الجملة في العربيّة. هذه أوجه من مرونة العربية التي جعلتها سيدة لغات العالم ، ولغة الغة الفكر، والمجتمع، والثقافة، وأي تعويق لها عن هذه السيادة يعد تراجعاً مخيفاً وتمزيقاً لوحدة الأمة العربية.

ج. انتشار اللغة العربية في بقاع العالم: آية عبقريتها ا. أتشار اللغة العربية قديماً يقول المستشرق "جورج بوست": "لغة العرب تفوق كل لغة في الانتشار إذا نظرنا إلى اتساع الأقطار التي لها فيها سلطان، وهي تفوق أيضاً كل لغة إذا نظرنا إلى التأثير في مستقبل الأعمال البشرية (الجندي ،

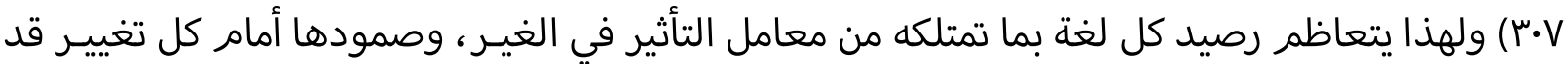


يطرأ على مفرداتها وتراكيبها وأصوات حروفها؛ ولهذا يقول محمد رشيد رضا: "وإن اللغة العربية من هذه إنها

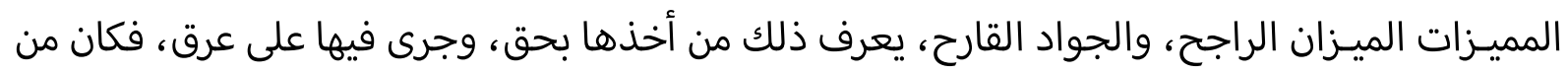

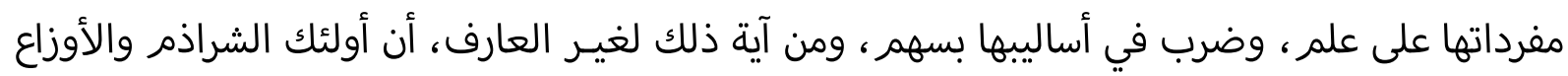

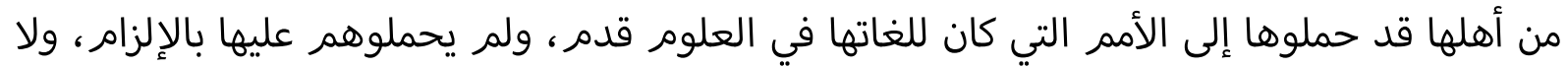

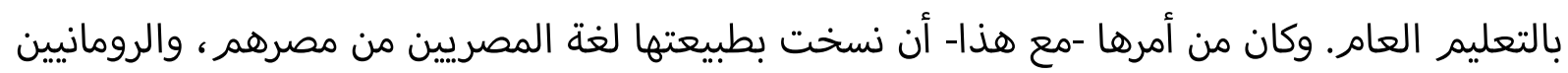

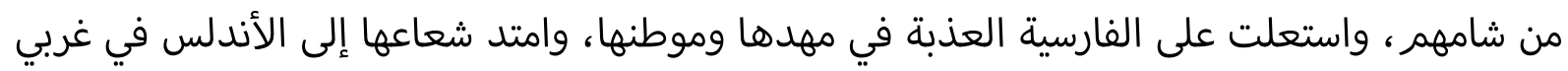

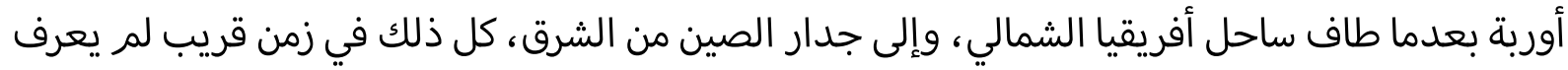
في التاريخ مثله للغة أخرى من لغات الفاتحين الذين يتخذون كل الوسائل لنشر لغاتهم (al-Jurjānī, 1981).

$$
\text { r. انتشار اللغة العربية في البلدان غير العربية في زمننا الحاضر }
$$

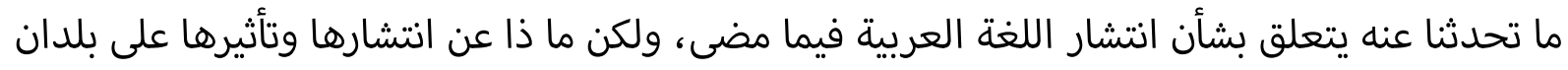

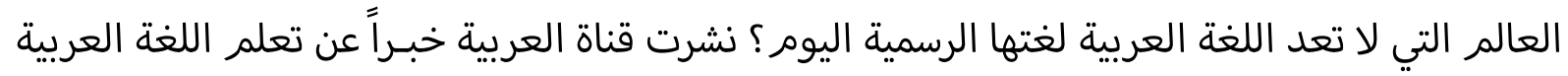

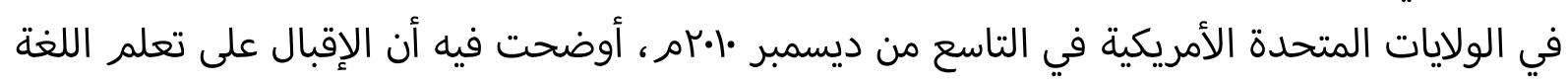

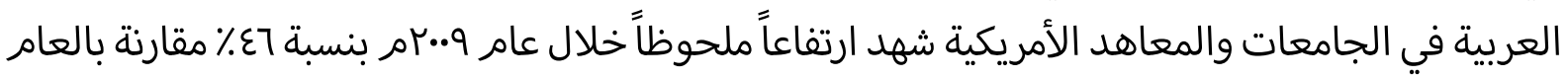

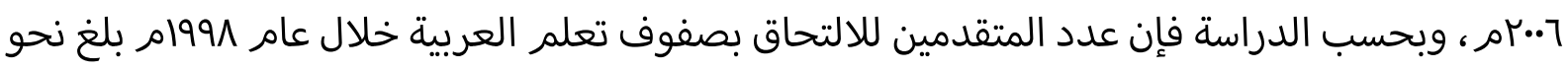

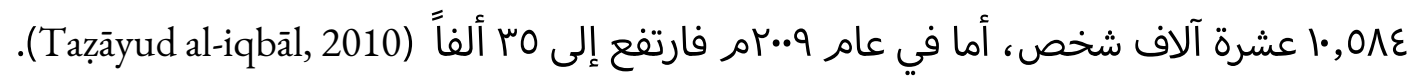

س. انتشار اللغة العربية في الولايات المتحدة الأمريكية

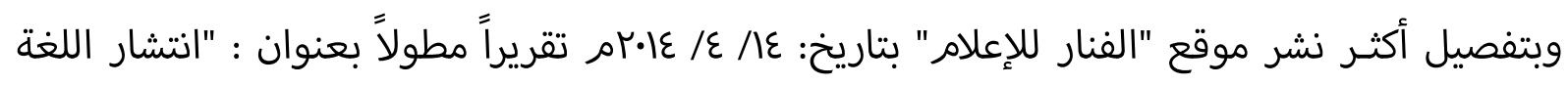

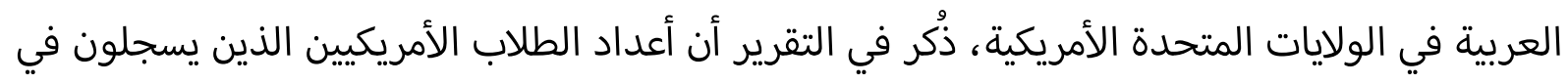

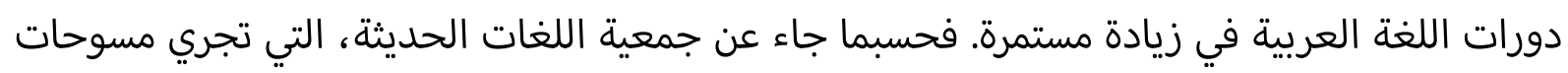

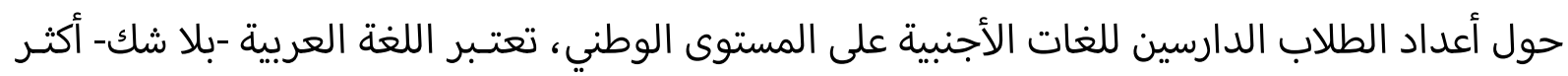

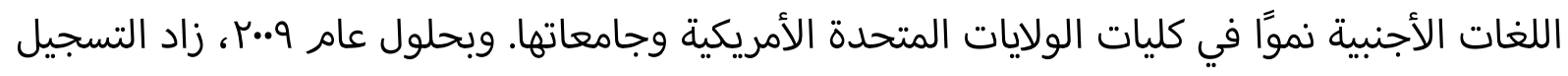

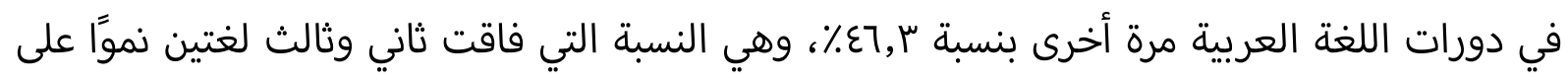
مستوى الولايات المتحدة وهما: اللغتان الكورية والصينية.

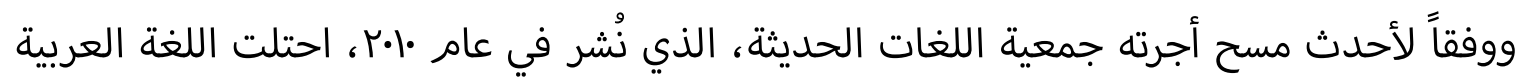

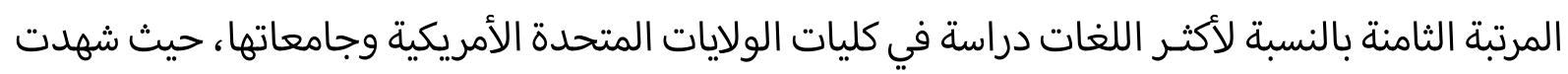

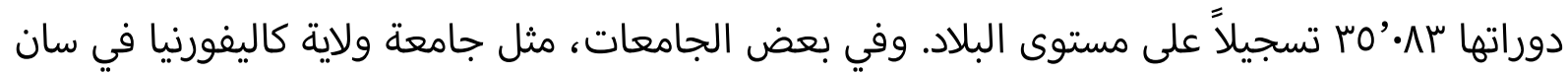
برناردينو، يفوق التسجيل في دورات اللغة العربية غيرها من اللغات التقليدية (Valosik, 2014). 
وأتذكر أنني في عام 17·rم قمت بزيارة لقسم اللغة العربية في جامعة تكساس في مدينة أوستن

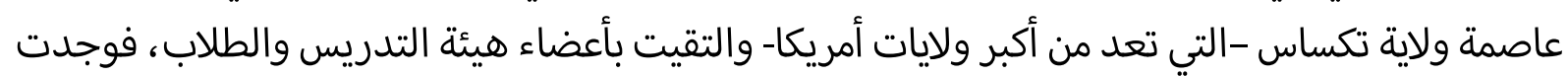
اهتماماً منقطع النظيـر في تعلم اللغة العربية وتعليمها، إذ يوجد لديهم برنامج يسمى "البرنامج العربي الرائد"، بدعم من الحكومة الأمريكية، ويهدف إلى تعزيز القدرة عند الطلاب الجامعيين لتعلم اللغة إلغة

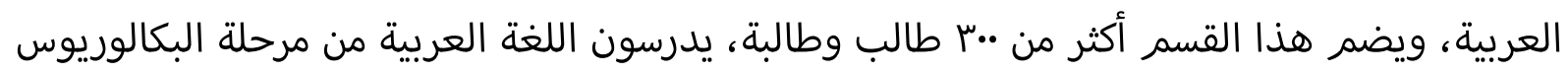
إلى مرحلة الدكتوراه، كما أن لديهم بعثات إلى مصر ودول المغرب العربي، وكثير منهم يدرس اللغة العربية للتعرف على الثقافة العربية ولأسباب أخرى.

ع. انتشار اللغة العربية في إسبانيا أما تعليم اللغة العربية في إسبانيا فإن الاهتمام بهذه اللغة قد زاد في السنوات الأخيرة؛ إذ كثـرت المراكز الجامعية والأكاديمية التي تختص بتعليم اللغة العربية وآدابها. وفي الربع الأخير من القرن العشرين

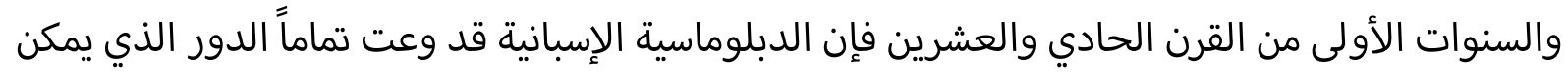
أن يلعبه العالم العربي والإسلامي على المستوى العالمي، وعرف منتصف القرن العشرين اهتماماً متزايداً بالثقافة واللغة العربية؛ إذ أنشئت أقسام جديدة للغة العربية والدراسات الإسلامية لمنح شهادة البكالوريوس في العديد من الجامعات الحكومية الإسبانية، وصل عددها الآن ثماني جامعات بها هذا الاختصاص، ثم هناك الكثير من الجامعات الإسبانية الأخرى التي تدرس العربية ضمن مناهجها كلغة (ب) (ج) (ج) أي لغير المختصين (al-Jabr, 2015, p. 81). 0. انتشار اللغة العربية في ألمانيا أما في ألمانيا، فإنه نتيجة لبعض الأحداث المهمة؛ التحق حوالي ••ع طالب جديد بالدورات والصفوف والدراسات الإسلامية -تشمل العربية- خلال الفصل الدراسي الشتوي عام rا•rمر، بالمقارنة مع العدد القليل قبل •l سنوات.

7. انتشار اللغة العربية في إندونيسيا أما في دول شرق آسيا، فتأتي على رأسها إندونيسيا، ففي دراسة قيمة عن اللغة العربية يذكر الباحثون أن

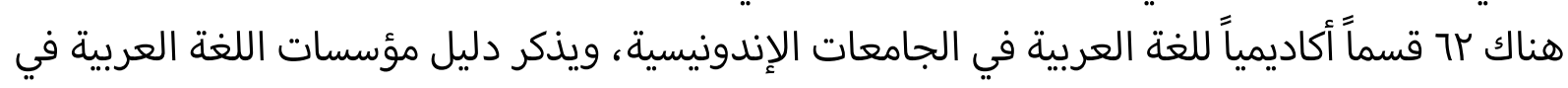

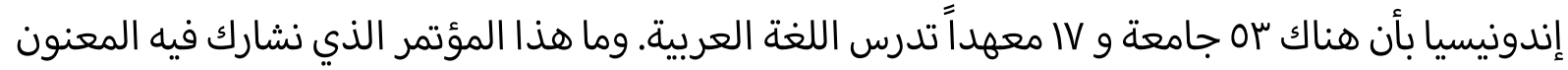
بـ"المؤتمر الدولي الأول لتعليم اللغة العربية للناطقين بغيـرها "الإستراتيجيات والمنتجات" في الفتـرة •اr/ 19 19 ام ، إلا واحد من اهتمامات جمهورية إندونيسيا باللغة العربية (Asnawi, 2015, p. 68). وفي إطار اهتمام جمهورية إندونيسيا باللغة العربية يلحظ تعاونها التام مع مركز الملك عبدالله الدولي لخدمة اللغة العربية حيث نفذ المركز في عام \ا•rم أكثر من ثلاث عشرة دورة تدريبية استفاد منها أكثر ••7 متدرب، كما ساهم المركز في استضافة برامج تدريبية في بعض الجامعات الإندونيسية وهي: 
جامعة مالانج الحكومية، وجامعة مالانج الإسلامية، وجامعة جاكرتا الحكومية، وجامعة الأزهر الإندونيسية، وجامعة مولانا مالك إبراهيم، وجامعة الرانيري الإسلامية الحكومية في باندا أتشيه. وفي وجاي الإطار ذاته، منحت جامعة مالانج الحكومية درجة الدكتوراه الفخرية، للأمين العام للمركز، نظيـر جهود المركز في خدمة اللغة العربية في العالم بوجه عام وفي إندونيسيا بوجه خاص، وذلك في حفل حضره عديد من المسؤولين والخبـراء من الجامعات الإندونيسية. كما عُقد برنامج مشترك تحت عنوان: (الملتقى التنسيقي لعمداء كليات اللغة العربية ورؤساء أقسامها

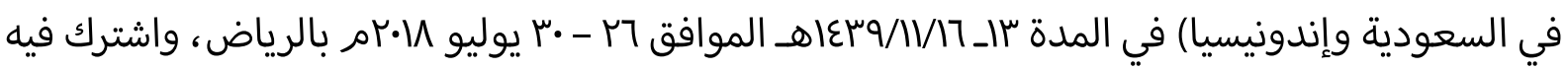
مسؤولو المؤسسات اللغوية في السعودية وإندونيسيا وعدد من الخبـراء في المجال اللغوي، وتضمن عقد في ثلاثة ملتقيات علمية تناقش: جهود المؤسسات والجامعات الإندونيسية في نشر اللغة العربية، والتخطيط اللغوي وإنشاء المؤسسات اللغوية وإدارتها، والتحديات التي تواجه تعليم العربية في إندونيسيا وأوجه التعاون مع المؤسسات السعودية (Markaz khidmat al-lughah, 2018).

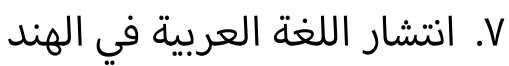
أما في الهند فتوجد بَ جامعة حكومية و •0 مؤسسة تعليمية أهلية تُعنى بتدريس اللغة العربية ومنح الدرجات العلمية فيها ('Ālim, 2015).

^. 1. انتشار اللغة العربية في الصين أما في الصين فيرى رئيس مجلس العلاقات الإسلامية الصينية دينغ هو في، أن اللغة العربية باتت لغة مهمة وقادرة على الربط بين بلاده وبين جميع الدول العربية والإسلامية، مبيناً أن الحاجة للغة الغينة العربية باتت ملحة، خاصة في هذا الوقت الذي بدأت فيه بلاد في إعادة طريق الحرير إلى الواجهة من جديد

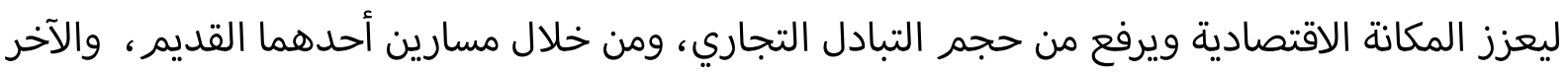

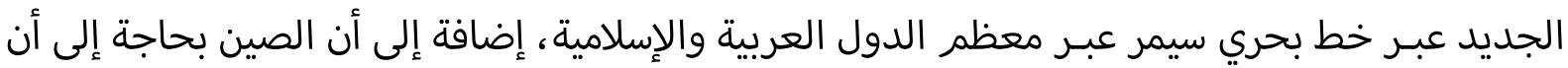

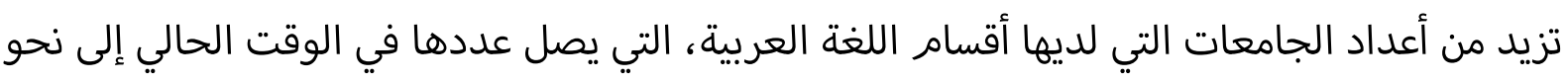

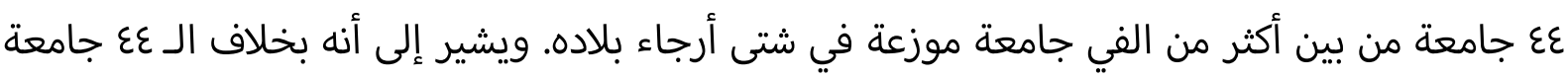
التي لديها أقسام لتعليم اللغة العربية، هناك ••r مدرسة إسلامية تعلم اللغة العربية ضمن مناهجها، وهي تقوم بتخريج نحو أربعة آلاف طالب سنوياً، بالإضافة إلى •ا ألف طالب يتعلمون اللغة عن طريق إسلى المساجد (Jāmi'ah Ṣīnīyah, 2015). وهكذا رأينا انتشار اللغة العربية في بقاع الأرض، واتساع الرقعة الجغرافية التي تتحدث العربية،

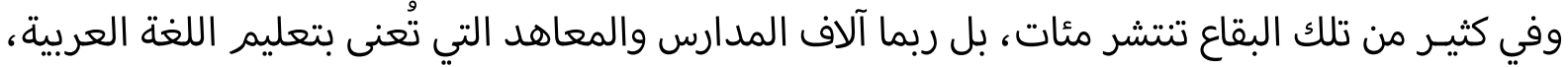
وتجعلها جزءاً أساساً من مناهجها الدراسية إن في التعليم العام أو في التعليم العالي. 
د. تأثير للغة العربية في اللغات الأخرى

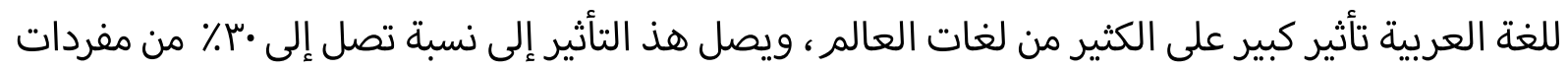

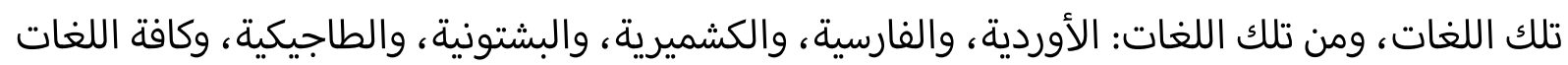
التركية، والكردية، والعبرية، والإسبانية، والصومالية، والسواحيلية، والتيغرينية، والأورومية، والهوسية، والمالطية، والبهاسا، وغيرها.

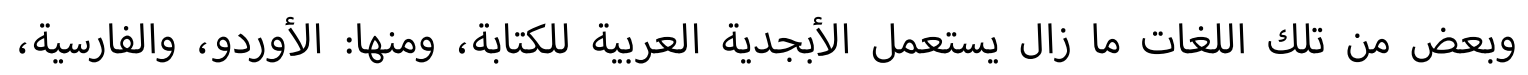

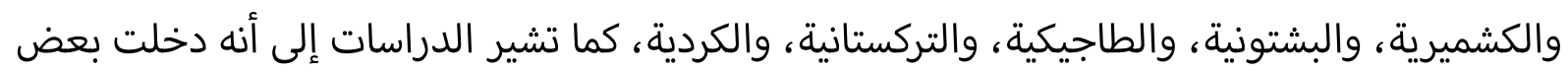

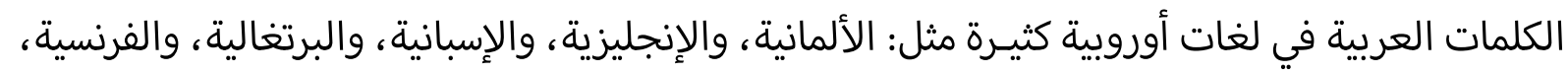

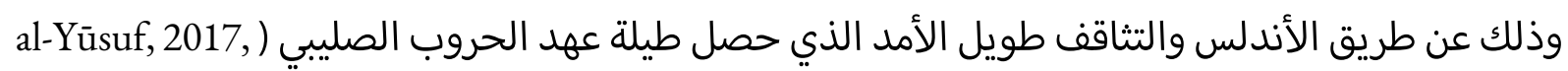

ولقد كان للغة العربية أثر على اللغة الإيطالية، "يقول رينالدي: لقد ترك المسلمون عدداً عظيماً من

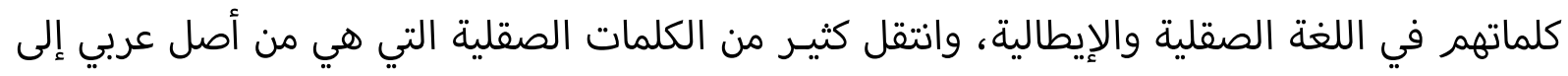

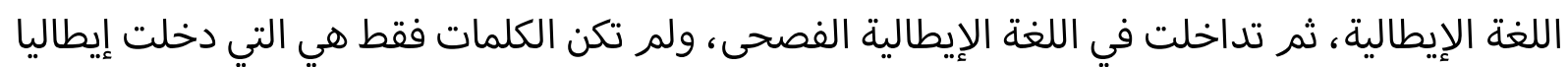

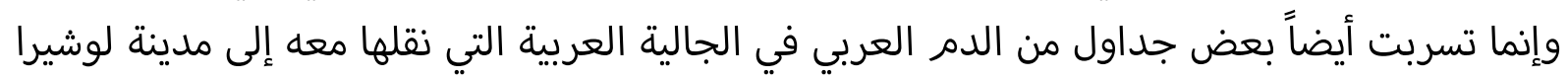

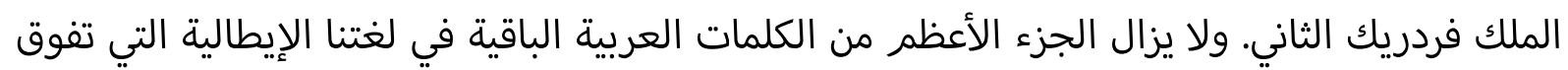

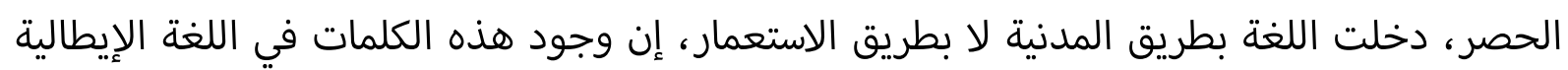
يشهد بما كان للمدنية العربية من نفوذ عظيم في العالم المسيحي (al-Jundī, 1982, p. 93).

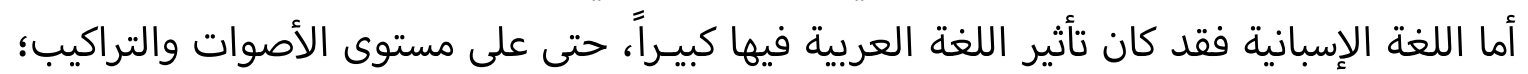

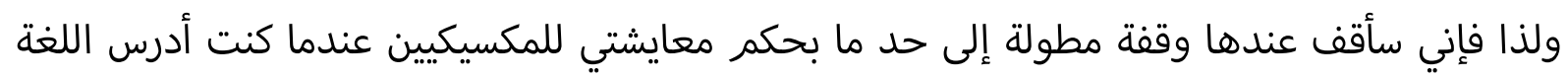

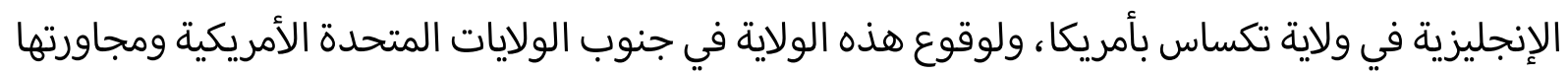

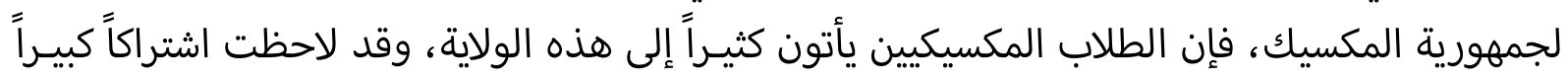

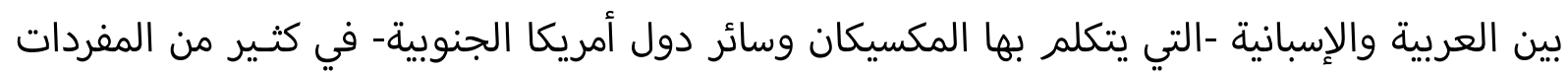

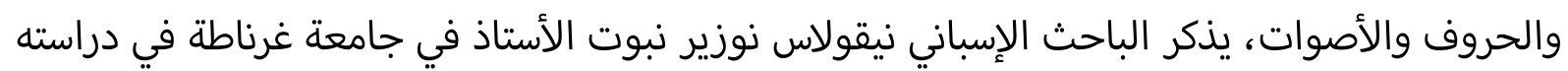

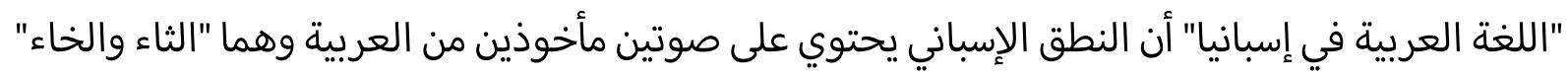

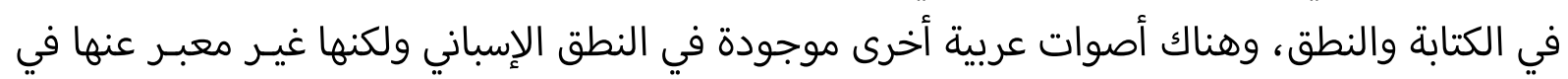

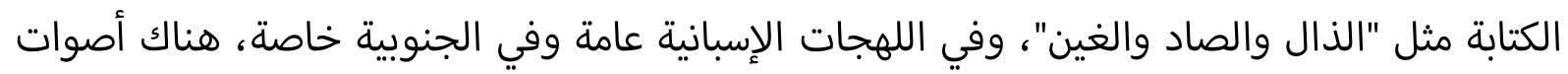

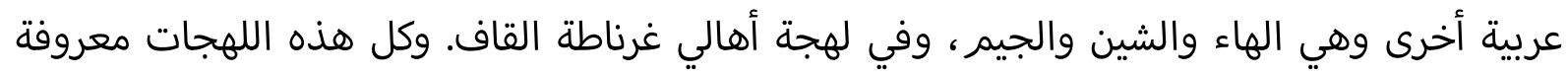

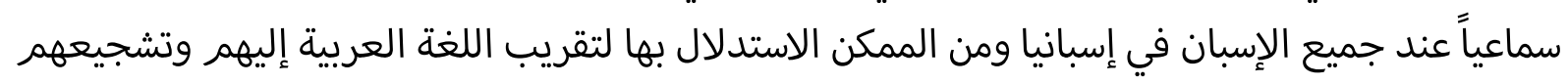

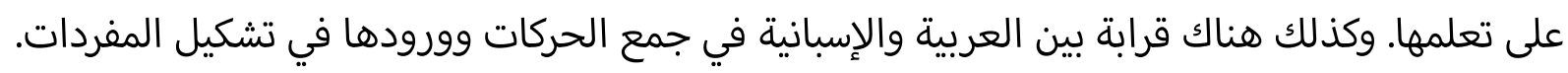
فالحركات العربية الثلاث: "الفتحة، الكسرة والضمة" موجودة في الإسباني (al-Atīq, 2015, p. 40). 
ولقد حاول الدارسون إحصاء عدد الألفاظ العربية في اللغة الإسبانية ونسبتها، حيث قام الدكتور

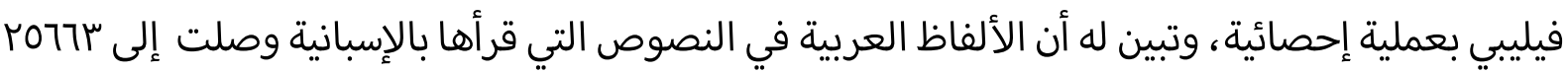

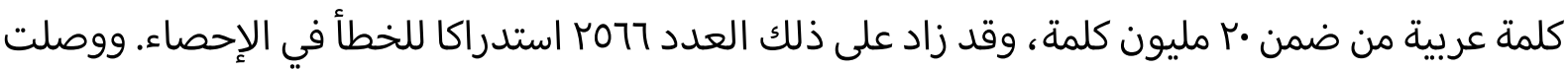

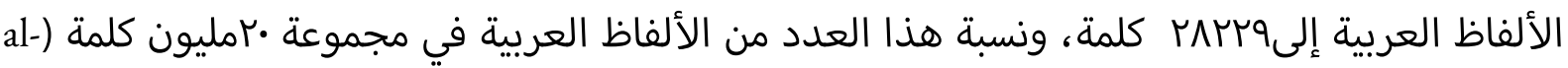
.('Atīq, 2015, p. 42 وجدير بالذكر أن أغلب الكلمات تم نقلها إلى الإسبانية بطريقة شفهية غيـر مكتوبة، وأن الإسبان

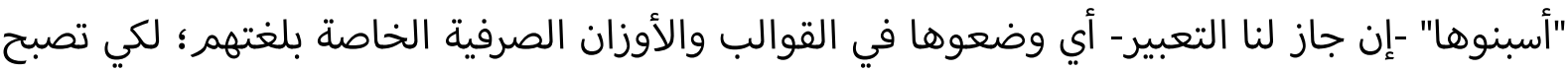

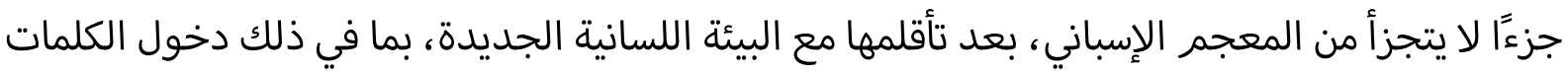

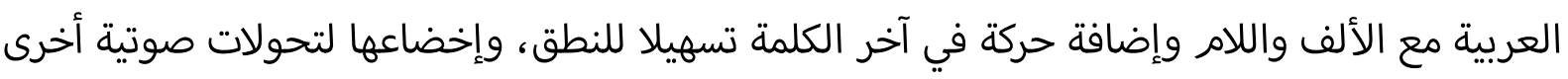

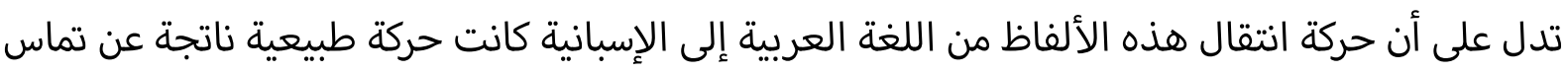

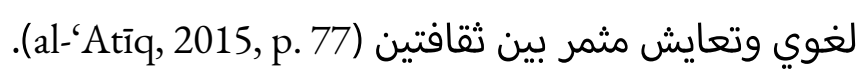

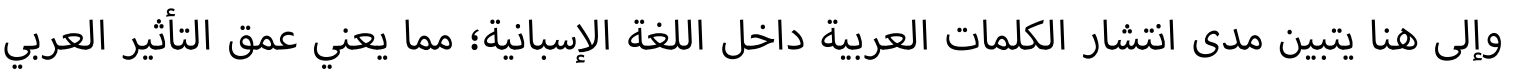

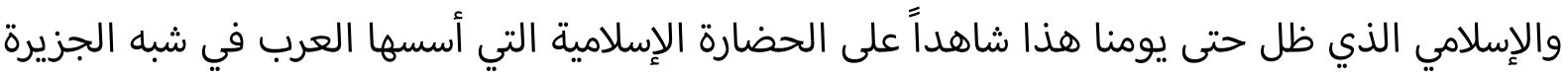

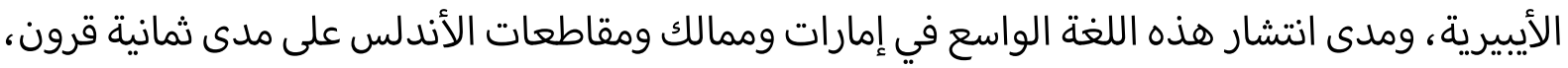

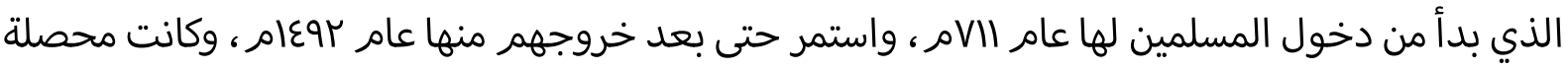

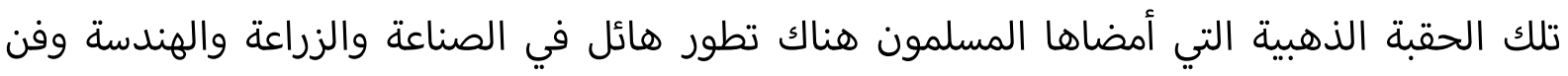
العمارة. ولعل السبب الرئيس في ذلك التأثير الكبيـر هو استيطان العرب المسلمين الذين أسسوا إسبانيا إسبانيا وأقاموا فيها حضارة راقية استمرت زهاء ثمانية قرون.

\section{الخاتمة}

نستطيع أن نصل في نهاية البحث إلى استخلاص عدد من النتائج التي أتت على النحو الآتي:

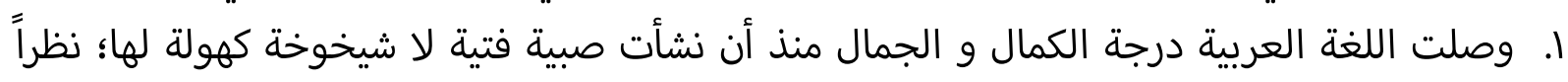
لارتباطها بالقرآن الكريم المحفوظ حتى قيام الساعة. r. سجلت اللغة العربية نقطة اهتمام البشرية جمعاء؛ لأنها حاملة لغة القرآن الكارئ الكريم ، وارتبطت بتعاليم الإسلام ومصدرية التشريع، فلا إسلام إلا بتعلم كتاب الله الذي تحمله تلك اللهابل اللغة.

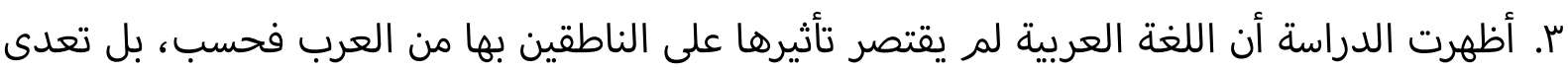

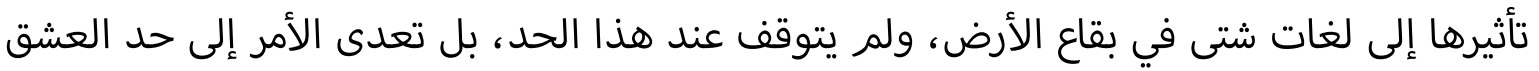
والانبهار بعبقرية هذه اللغة وجمالها الساحر.

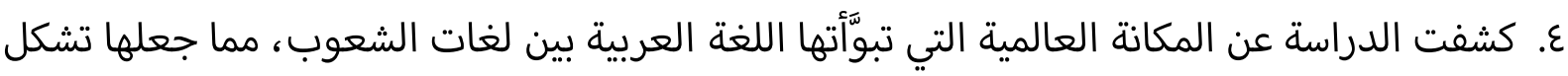

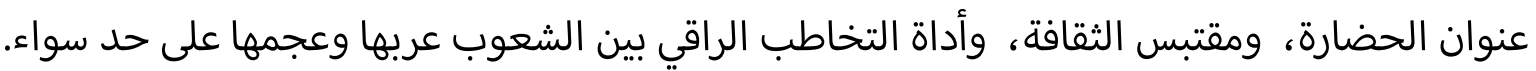


0. سجلت الدراسة الاهتمام العالمي باللغة العربية من دول، ومنظمات، وهيئات، ومفكرين، وعلماء، وباحثين على اختلاف الألسنة والألوان والبقاع. 7. أبانت الدراسة المزايا والخصائص والسمات التي تفردت بها اللغة العربية دون ما سواها من أخواتها من اللغات السامية. N. توصلت الدراسة إلى الوظائف التي تؤديها اللغة العربية على المستوى الصوتي والاشتقاقي والتركيبي. ^. أوضحت الدراسة أسباب انتشار اللغة العربية في أمريكا، والصين، والهند، ودول شرق آسيا، وإسبانيا، وكافة دول أوروبا، وتوصلت إلى أن أهم سبب جعلها تنتشر هو عبقريتها الفذة وجاذبيتها الذكية بما

$$
\text { في إضمامتها من مفردات وأساليب وتراكيب وألفاظ. }
$$

9. كشفت الدراسة عن تغلغل اللغة العربية في جميع لغات العالم، واشتراكها معها في كثير من من من المفردات والأصوات، وهذا آية على تأثير اللغة العربية الكبيـر على هذه اللغات من خلال التعايش في السلمي وحركة الحياة الطبيعية والأخلاق العالية التي كان يتمثلها المسلمون الفاتحون لتلك البلدان آن

ا. تنبأت الدراسة بمستقبل زاهر للغة العربية؛ نظراً لما تشهده المحافل الدولية والجامعات الأجنبية من احتفاء بهذه اللغة، واهتمام بتعلمها وتعليمها في كافة المستويات الدراسية ابتداءً بمدارس التعليم العام وانتهاء ببرامج الدراسات العليا.

\section{المراجع}

\section{al-Qur'ān al-Karim}

Asnawi, T. (Ed.). (2015). Dalìl mu'assasāt al-lughah al-'Arabìyah fì Indūnīsīyā. Riyadh: Markaz alMalik 'Abd Allāh ibn 'Abd al-'Azīz al-Duwalī li-Khidmat al-Lughah al-'Arabīyah.

'Abd al-Qādir, I. (2017, August 9). Tațawwur al-lughah al-'Arabīyah. Mawdū'. Retrieved from https://mawdoo3.com/تطور_اللغة_العربية

'Ālim, Ṣ. (2015). Tārìkh al-lughah al-'Arabìyab wa-wāqi'ubā fì al-Hindi. Riyadh: Markaz al-Malik 'Abd Allāh ibn 'Abd al-'Azīz al-Duwalī li-Khidmat al-Lughah al-'Arabīyah.

al-'Atīq, M. 'A. (Ed.). (2015). al-Lughab al-'Arabìyah fì Isbānīyā. Riyadh: Markaz al-Malik 'Abd Allāh ibn 'Abd al-'Azīz al-Duwalī li-Khidmat al-Lughah al-'Arabīyah.

Brockelmann, C. (1977). Fiqh al-lughah al-sāmīyah (R. 'A. al-Tawwāb, Trans.). Riyadh: Jāmi'‘at alMalik Su'ūd.

al-Bāqūrī, A. H.. (n.d.). Athar al-Qur'ān fì al-lughah al-'Arabìyah. Ṭ. Husayn (Ed.). Cairo: Dār al$M a a^{a} a ̄ i f$.

Ibn Kathīr. (n.d.). Tafsīr al-Qur'ān al-'ażìm. Beirut: Mu'assasat al-Rayyān li-al-Ṭibā'ah wa-al-Nashr wa-al-Tawzī'.

Jāmi'ah Ṣinniyah tabḥath tațīir asālībihā fī tadrīs al-lughah al-'Arabīyah. (2015, January 5). Sabq. Retrieved from https://sabq.org/UWugde

al-Jabr, B. N. (2015). Tajārib ta 'ìm al-lughah al-'Arabìyah fì Awrübā': 'Arad wa-taqwìm. Riyadh: Markaz al-Malik 'Abd Allāh al-Duwalī li-Khidmat al-Lughah al-'Arabīyah. 
al-Jundī, A. (1982). al-Fuṣhá lughat al-Qur'ān. Beirut: Dār al-Lubnānī.

al-Jurjānī, 'A. Q. (1981). Asrār al-balāghah fĩ 'ilm al-bayān. M. R. Riụá (Ed.). Beirut: Dār alMa'rifah.

Markaz khidmat al-lughah al-'Arabīyah yudashshin barnāmijah al-'ilmī wa-al-tadrībī fī Indūnīsīyā. (2018, July 16). Sabq. Retrieved from https://sabq.org/LGHYWP

al-Mubārak, M. (1979). Naḥw wa'y lughawī. Beirut: Mu'assasat al-Risālah.

al-Nūrī, 'A. H. (2014, December 12). Murūnat al-lughah al-'Arabīyah. Majma' al-Lughah al'Arabiyah 'alá al-Shabakah al-'Alāmīyah. Retrieved from http://www.m-aarabia.com/vb/showthread.php? $\mathrm{t}=7203$

al-Shāfíī. (n-d.). Ahkām al-Qur'ān li-al-Shāfìì. A. B. al-Naisābūrīì (Ed.). Beirut: Dār Ihỵā’al-'Ulūm. Taẓāyud al-iqbāl 'alá ta'allum al-lughah al-'Arabīyah fī al-jāmi'at wa-al-ma'āhid al-Amrīkīyah. (2010, December 09). al-Arabiyah. Retrieved from https://www.alarabiya.net/articles/2010/12/09/128970.html

'Ubaydillāh, M. (2014, September 5). 'Ālamīyat al-lughah al-'Arabīyah. Maghris. Retrieved from https://www.maghress.com/alalam/61279

Valosik, V. (2014, April 14). Arabic is blooming in the United States. Al-Fanar Media. Retrieved from https://www.al-fanarmedia.org/2014/04/arabic-blooming-u-s/

al-Yūsuf, S. b. S. (Ed.). (2017). Qimat al-lughah al-'Arabìyah. Riyadh: Markaz al-Malik 'Abd Allāh ibn 'Abd al-'Azīz al-Duwaī li-Khidmat al-Lughah al-'Arabīyah.

Zaydān, J. (2012). Tārīkh ādāb al-lughah al-'Arabīyah. Cairo: Mu'assasat Handāwī li-al-Ta'līm waal-Thaqāfah. 